\title{
A Proposed Classification Method in Menu Engineering Using the K-Nearest Neighbors Algorithm
}

\author{
Nina Setiyawati ${ }^{\mathrm{a}, *}$ \\ ${ }^{a}$ Faculty of Information Technology, Universitas Kristen Satya Wacana, Salatiga, 50715, Indonesia \\ Corresponding author: "nina.setiyawati@uksw.edu
}

\begin{abstract}
In the culinary business, the menu is crucial; therefore, the performance of each menu needs to be known to maintain business continuity. Menu engineering is a special technique used to see the performance comparison of each menu item. This research proposes modeling menu engineering with a new approach in classifying menu items using the k-Nearest Neighbors (k-NN) algorithm using the sales training data of sales data in 2019 belonging to one of the micro, small and medium-sized enterprises in the culinary subsector in Salatiga, Indonesia. In the modeling, the popularity index (menu mix) and item contribution margin are used as variables, while the menu item class is used as the label attribute of the classification. Determination of the $k$ value in the $k-N N$ algorithm was done by the experimental method so that it produces the most optimal $k$ based on the highest accuracy value, while the distance calculation on k-NN was done using euclidean distance. Evaluation of the model was done using 10-fold cross-validation with four performance evaluation criteria, namely weighted mean recall, weighted mean precision, accuracy, classification error. Based on the evaluation results, an accuracy of $\mathbf{9 6 . 8 4 \%}$ was obtained; thus, the proposed model is considered to have given good and accurate results. This proposed model has been implemented in MSME sales data to classify menu items. The results of this classification were used as a basis for recommending menu engineering strategies to MSMEs.
\end{abstract}

Keywords - Menu engineering; k-NN; classification; 10-fold cross-validation.

Manuscript received 8 Jun. 2020; revised 18 Feb. 2021; accepted 28 Mar. 2021. Date of publication 31 Aug. 2021. IJASEIT is licensed under a Creative Commons Attribution-Share Alike 4.0 International License.

\section{INTRODUCTION}

Culinary is one of the sustaining mainstays of Indonesia's tourism sector and creative economy [1], [2] with a contribution of $41 \%$ of the total revenue of the tourism sector and creative economy in 2017 [3]. This can also be seen from the employment in the culinary industry, which is the secondhighest in the creative industry reached $29.17 \%$ [4]. This confirms that culinary plays an important role in job creation and economic growth [5]. However, the culinary industry is a very competitive environment, resulting in a failure rate of close to $60 \%$ in the first three years of opening [6], where one of the causes is poor menu choices [7]. In the culinary business, the menu is a crucial matter, where it is a core product [8], [9] which largely determines how operations will be organized and managed, also controlling many aspects of the culinary business [10], [11]. Therefore the performance of each menu needs to be known to maintain business continuity.

Menu engineering is a special technique used to see the performance comparison of each menu item [12], [13]. By knowing the menu's performance, it is possible to estimate future sales [14] so that an appropriate design and marketing strategy can be determined. Menu engineering can help improve managerial effectiveness, create menu contents and the structure of menu prices, which must be very well planned [15]. This, in its implication, can maximize restaurant profits [14]. Thus, the right engineering menu is very important for business success [16].

In menu engineering, sales history data is needed for analysis. Some elements of the required sales data are menu prices, cost of goods sold, profits, and menu popularity index. This research proposes a menu engineering model using the $\mathrm{k}-\mathrm{Nearest}$ Neighbors (k-NN) algorithm, which is an instancebased learning algorithm [17]-[20] that can identify groups of data by looking at similar historical behavior represented with the value of neighbors proximity [21]-[26] and then validated by a large number of neighbors [27] on the dependent variable.

With k-NN, a simple and effective classification method [28], modeling of menu item classification based on popularity index and contribution margin [29]-[31] is done using training data, where the results can be used as a basis for classifying new menu items in the test data. The process is done by calculating the distance of the menu item points on 
the test data with the menu item points on the training data using the Euclidean formula [32]. The model result is expected to more dynamically and accurately help group menu performance because it is based on the closest distance to the history of classifying menu items.

\section{MATERIAL AND MethoD}

The menu engineering concept was introduced by Kasavana and Smith, who grouped menu items in four quadrants formed from a $2 \times 2$ matrix based on the intersection of the popularity index and contribution margin [29], [33], [34] as shown in Fig. 1.

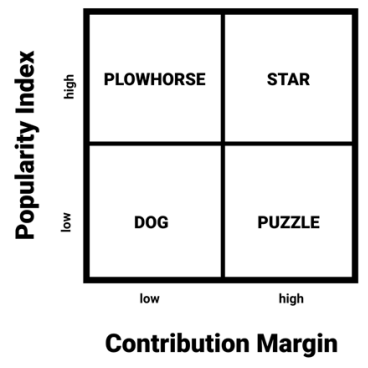

Fig. 1 Menu Engineering Matrix

The contribution margin is the result of reducing the sale price of menu items with the cost of menu items, while the popularity index or menu mix is the number of the item sold in the menu divided by the total number of items sold of all menus stated in percentage [29], [35]. The contribution margin (CM) formula and the popularity index (MM) are seen in Formulas (1) and (2).

$$
\begin{gathered}
C M=\text { Item Price }- \text { Food Cost } \\
M M \%=\frac{\text { number of the item sold }}{\text { total number of items sold }} \times 100 \%
\end{gathered}
$$

Menu engineering has been widely used as an approach in analyzing menus [36], [37]. In addition, several studies have carried out modeling of the menu engineering with a different approach, such as LeBruto et al. [38]., who inserted labor into the model, so the matrix becomes $3 \times 2$ and produces eight quadrants. In addition, Horton also included labor estimates in the contribution margin [39]. In 2017, Tom and Annaraud [16] applied the fuzzy multi-criteria decision making (FMCDM) technique to model the engineering menu into nine quadrants. Setiyawati and Bangkalang also modeled menu engineering using a two-step cluster by adding one category variable, namely the item category, to see the dominant menu categories in each later formed cluster [31].

In this research, menu engineering modeling was done using k-NN. The stages in this study can be seen in Fig. 2, which consists of 3 main stages, namely: 1) Pre-processing; 2) k-NN model; 3) Strategy Recommendations.

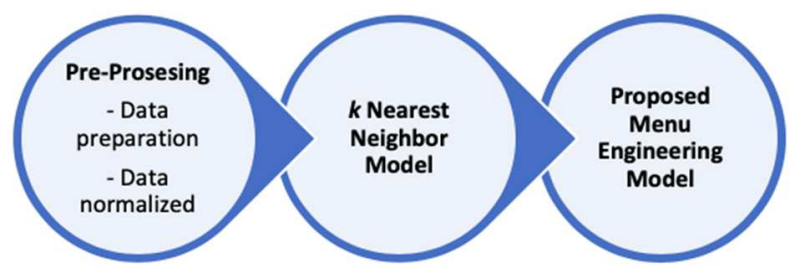

Fig. 2 Research Stages

\section{A. Pre-Processing}

The initial data set used in this study was sales data of one of the micro, small and medium enterprises (MSMEs) in the culinary field in Salatiga, Indonesia, in the period of AugustDecember 2019, which had 120 menu items and 73,008 transaction data. The variables used in the proposed menu engineering model are the popularity index (menu mix) and item contribution margin, and the menu item class as the label attribute of the classification.

There were differences in the range of attributes in the popularity index variable and item contribution margin, so data transformation was needed [40]. The data transformation method in this modeling used Z-score normalization, a method for normalizing data based on the average distribution and distribution of data in the sample [41], [42]. The Z-Score Normalization formula is seen in Formula (3).

$$
x b=\frac{\mathrm{xa}-\overline{\mathrm{x}}}{\sigma}
$$

Where:

$$
\begin{array}{ll}
x b & =\text { new value } \\
\mathrm{xa} & =\text { old value } \\
\bar{x} & =\text { average } \\
\sigma & =\text { standard deviation }
\end{array}
$$

The purpose of this value transformation is so that the minimum or maximum values of the resulting data are standardized and at the same attribute range to produce more accurate calculation results. Normalization results from the data set are shown in Table 1.

TABLE I

NORMALIZATION DATA SET

\begin{tabular}{cccc}
\hline Item Code & $\begin{array}{c}\text { Popularity } \\
\text { Index } \%\end{array}$ & Item C.M. & $\begin{array}{c}\text { Menu Item } \\
\text { Class }\end{array}$ \\
\hline 1 & -0.385 & -0.579 & DOG \\
2 & -0.279 & -15867 & DOG \\
3 & -0.172 & 147251 & PUZZLE \\
4 & -0.289 & 0.4654 & PUZZLE \\
5 & -0.524 & 0.7029 & PUZZLE \\
$\ldots$ &.. & $\ldots$ & \\
120 & 0.1314 & -11440 & DOG \\
\hline
\end{tabular}

\section{B. $k$-Nearest Neighbors Model}

To obtain a good and accurate processing model, an evaluation of the model must be made. This study used k-fold cross-validation as a model evaluation method. $\mathrm{k}$-fold crossvalidation is one method that is often used to evaluate models or algorithms [42], [43]. The higher the k-fold value can reduce the level of bias of the performance estimator, and the variant of the performance estimator increases; thus, the algorithm's output is more accurate and has more variability [42]. The main idea in the k-fold cross-validation method is to divide the sample data into the same set of $\mathrm{k}$-fold where $k$ is the number of data sharing partitions [44]. K-fold used in evaluating this model was 10 -fold, so the data was divided into ten partitions, which means nine partitions were used as training data and the rest as testing data. Training data was carried out ten times using different training partitions and testing data. To calculate the performance of this model, the total average performance of each partition experiment was calculated. Fig. 3 shows the stages carried out to evaluate the model being built. 


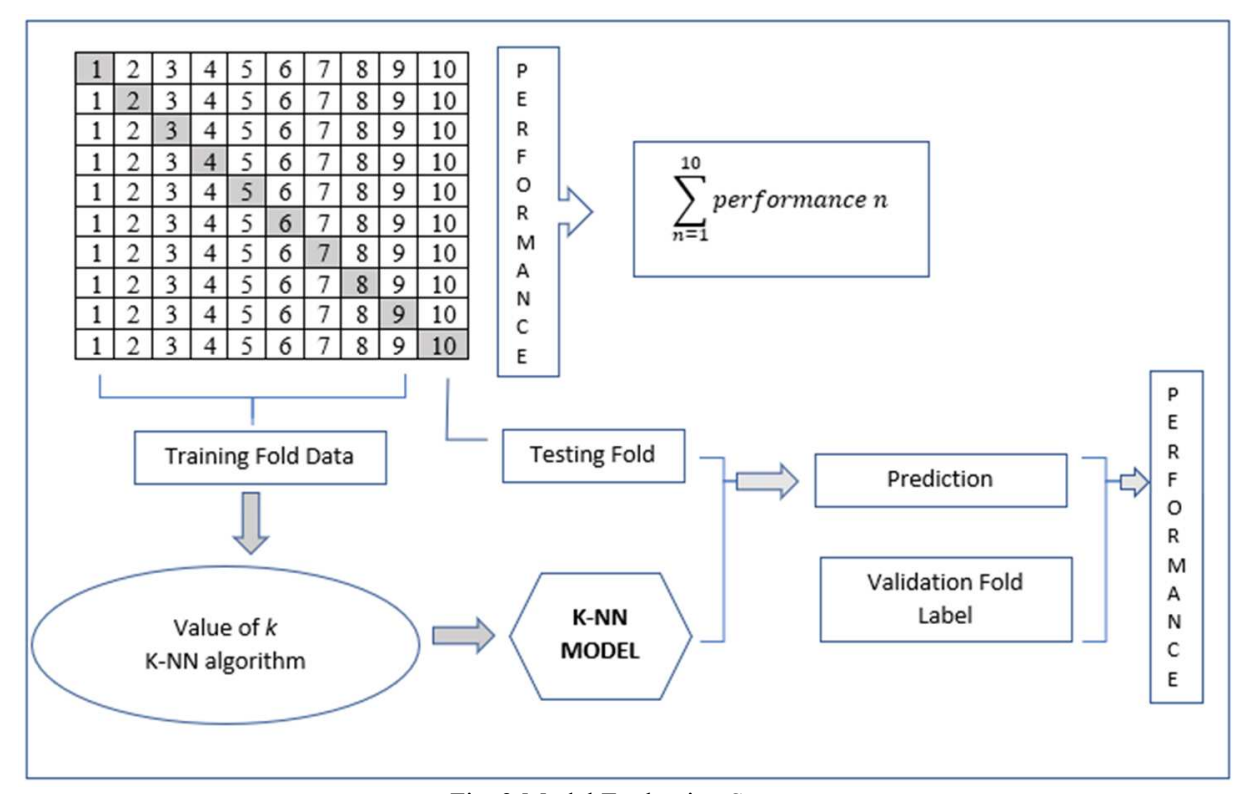

Fig. 3 Model Evaluation Stages

In Fig. 3, after the division of training fold data, the $\mathrm{k}$ value was determined, which is the number of nearest neighbors in which it is the basis of the classification on the k-NN algorithm [27], [45]. So that the determination of the optimal $k$ value, in this case, means that $k$ has the highest accuracy, can produce an accurate classification. The determination of the $k$ value in this study used an experimental method with $\mathrm{k}-$ fold cross-validation [46]. The experiments carried out resulted in performance, as shown in Table 2.

TABLE II

EVALUATION VALUE OF $K$

\begin{tabular}{ccc}
\hline No & Value of $\boldsymbol{k}$ & Accuracy \\
\hline 1 & 3 & $92.50 \%$ \\
2 & 5 & $93.33 \%$ \\
3 & 7 & $93.33 \%$ \\
4 & 9 & $92.50 \%$ \\
5 & 11 & $91.67 \%$ \\
6 & 13 & $91.67 \%$ \\
7 & 15 & $91.67 \%$ \\
8 & 17 & $90.83 \%$ \\
9 & 19 & $90.00 \%$ \\
10 & 21 & $90.83 \%$ \\
\hline
\end{tabular}

Based on Table 2, out of 10 trials using different $\mathrm{k}$ values, the highest $\mathrm{k}$ accuracy obtained was at values $k=5$ and $k=7$. Because the highest accuracy was in the two $k$ values, an experiment was conducted on both values to choose one $k$ value. The test results found that the highest accuracy was at $k=5$.

The k-NN algorithm uses distance calculation for the formation of the nearest neighbors. The distance calculation method used was Euclidean distance, which measures two distances at different points [47]. The Euclidean distance equation is seen in Formula (4).

$D(i, j)=\sqrt{\left(X_{1 i}-X_{1 j}\right)^{2}+\left(X_{2 i}-X_{2 j}\right)^{2}+\cdots+\left(X_{k i}-X_{k j}\right)^{2}} \cdots$

In Formula $4, D(i, j)$ is the distance of data to $i$ to the central point $j, X_{k i}$ is the data to $i$ on the attribute data to $k$, and $X_{k j}$ is the center point to $j$ on the attribute to $k$. Data grouping was done by entering data $\mathrm{D}(\mathrm{i}, \mathrm{j})$ in a Class category according to the number of the $k$ nearest neighbors, where the determination of k-nearest neighbors is seen from the order of the shortest distance.

\section{RESULT AND DISCUSSION}

\section{A. Model Menu Engineering Proposal}

Menu Engineering is a tool that can be used to compare the performance of each menu item and help MSME gain valuable insight into MSME menu to make more strategic business decisions. In the menu engineering, the menu is categorized into four categories which are STAR, PUZZLE, PLOWHORSE, and DOG. This study proposes the modeling of menu engineering with a new approach in classifying menu items using the k-NN algorithm. Table 3 results from the accuracy prediction on each menu item class, where the class represents a category from the menu engineering model in this study.

TABLE III

ACCURACY TABLE

\begin{tabular}{lccccc}
\hline & DOG & STAR & & & \\
& & & & & \\
& 52 & 3 & 0 & 0 & $94.55 \%$ \\
$\begin{array}{l}\text { Prediction } \\
\begin{array}{l}\text { DOG } \\
\text { Prediction }\end{array}\end{array}$ & 1 & 56 & 3 & 0 & $93.33 \%$ \\
$\begin{array}{l}\text { PUZZLE } \\
\text { Prediction }\end{array}$ & 0 & 0 & 0 & 0 & $0.00 \%$ \\
$\begin{array}{l}\text { STAR } \\
\text { Prediction }\end{array}$ & 1 & 0 & 0 & 4 & $80.00 \%$ \\
$\begin{array}{l}\text { PLOWHORSE } \\
\text { Class Recall }\end{array}$ & $96.30 \%$ & $94.92 \%$ & $0 \%$ & $100.00 \%$ & \\
\hline
\end{tabular}

Based on Table 3, the accurate prediction of each item class is obtained according to precision and recall. Precision and recall are calculations to determine how accurately the algorithm produces correct predictions. Precision is the probability of the correct prediction given by the algorithm, while recall is the probability of a correct prediction identified 
according to each menu item class [48], [49]. In other words, class precision is the correct item prediction ratio compared to all the prediction results that correspond to that class. At the same time, class recall is the correct item prediction ratio compared to all actual results for the class.

The result obtained in Table 3 shows that the dog category has a class precision of $94.55 \%$. This means, of the 55 predicted menu items on the class dog, there are 52 corresponding menu items. As for the class recall has a performance of $96.30 \%$, which means that of the 54 actual menu item data on the class dog, there are 52 corresponding prediction results. The puzzle category has $93.33 \%$ class precision and $94.92 \%$ class recall, items in the star category have $0 \%$ class precision and class recall, and articles in the plowhorse category have $80 \%$ class precision and $100 \%$ class recall. K-fold cross-validation performs iterations as many as the number of $\mathrm{k}$ values, resulting in different performance outputs. Table 4 is an evaluation of the average performance of the proposed model.

TABLE IV

MOdel PERformance Evaluation

\begin{tabular}{lc}
\hline \multicolumn{1}{c}{ Criteria } & Micro Average \\
\hline Weighted Mean Recall & $98.33 \%$ \\
Weighted Mean Precision & $87.08 \%$ \\
Accuracy & $96.84 \%$ \\
Classification Error & $3.16 \%$ \\
\hline
\end{tabular}

Table 4 is the result of evaluating the average performance of the algorithm being modeled. Evaluations using 10-fold cross-validation are based on some criteria. The first criterion is weighted mean recall. The average obtained from the weighted mean recall is $98.33 \%$, so it can be concluded that the probability of the predicted value of the actual data is very good. The next criterion is weighted mean precision. This algorithm model's average weighted mean precision is $87.08 \%$, so the item prediction probability is considered good. Then another criterion is the accuracy value. The accuracy value of the proposed algorithm is $96.84 \%$, and the classification error is $3.16 \%$.

Based on the performance evaluation in Table 4, algorithm modeling is considered to have given accurate results. With this basis, a model was implemented on the MSME sales data. The data set used as input data was menu sales data in January-March 2020, with a total of 95 menu items. The results of this classification were used as a basis for recommending menu engineering strategies to MSMEs. The classification results obtained are seen in Table 5.

TABLE V

OUTPUT MENU ENGINEERING USING K-NN MODEL

\begin{tabular}{ll}
\hline \multicolumn{1}{c}{ Item Class } & \multicolumn{1}{c}{ Item Code } \\
\hline STAR & $18,67,71,89$ \\
PUZZLE & $3,6,11,21,22,25,26,27,31,32,33,34,37,38$, \\
& $39,41,42,43,44,45,46,47,48,51,53,57,58$, \\
& $59,60,61,62,66,70,72,73,74,81,82,83,84$, \\
& $85,86,90,92,93,95$ \\
PLOWHORSE & $16,23,69$ \\
DOG & $1,2,4,5,7,8,9,10,12,13,14,15,17,19,20$, \\
& $24,28,29,30,35,36,40,49,50,52,54,55$, \\
& $56,63,64,65,68,75,76,77,78,79,80,87$, \\
& $88,91,94$ \\
\hline
\end{tabular}

Table 5 is the result of menu engineering classification based on the proposed modeling. Based on the classification results, there are four menu items in the STAR class. In the PUZZLE class, there are 46 menu items. The PLOWHORSE class has three menu items, while the DOG class has 42 menu items. Based on the results of the classification of each menu item, MSMEs can choose strategies that can be used to increase business profits by applying strategy to menu engineering.

\section{B. Menu Engineering Strategy}

1) STAR: STAR classification has a high popularity index and provides high contribution margins [29], [35]. Some strategies that can be applied in the STAR classification are as follows:

- Maintaining the quality of the menu, portions, and appearance according to the applicable recipe standards [16], [36]

- Increasing the selling price periodically by taking into account the increase in existing demand and the selling price of competitors [31].

- Customers tend to order items that "stand out", so menus in this classification can be placed in the visible section.

2) PUZZLE: PUZZLE classification is a menu with a low popularity index but gives a high contribution margin [29], [35]. Referring to these conditions, several strategies must be implemented so that the menus become more popular while still ensuring that the contribution margin does not become low. The strategies that can be applied are as follows:

- Putting menu information in the most visible part to attract customer attention [16].

- Lowering prices while still paying attention to appropriate pricing strategies such as profit margin conditions, cost of goods sold, and competitors' selling price.

- Give discounts on food delivery applications and/or promote the menu through social media to attract customers [31].

- Offering larger portion sizes [37] or providing "addons" to increase the menu item's value.

3) PLOWHORSE: The PLOWHORSE classification contains menus with a high popularity index but gives a low contribution margin [29], [35]. Therefore, efforts must be made to increase the benefits of this classification. Some strategies that can be applied in the PLOWHORSE classification are as follows:

- Increasing the selling price of food gradually by taking into account the number of requests [36].

- Reducing food costs, such as reducing the number of ingredients orders, efficiency of menu processing, reducing portion sizes [36], [37] or simplifying presentation while maintaining the quality and aesthetic appearance of the food.

- Seeing that this classification consists of menus favored by many customers, these menus can be placed far or hidden from the focal point of the menu to attract customers to more profitable menus [36]. 
4) DOG: The DOG classification contains menus with a low popularity index and contribution margin [29], [35], or it can be said that the DOG classification is menus that are not popular and unprofitable. Some things that can be applied for menus in the DOG classification are as follows:

- Removing or eliminating the menus. This is highly recommended to reduce substantial business burden [31].

- Minimizing the number of menus in this classification as much as possible. This can be interpreted as an effort to move the menu to another classification. For example, transferring it to the PLOWHORSE classification by increasing its popularity by creating menu packages from this classification combined with foods or drinks from other classifications with high popularity.

\section{CONCLUSION}

This study proposes the modeling of menu engineering with a new approach in the classification of menu items using the k-NN algorithm. The training data used was the MSMEs sales data in 2019. Model evaluation was done using 10-fold cross-validation with four performance evaluation criteria: weighted mean recall, weighted mean precision, accuracy, and classification error. Based on the evaluation results, $98.33 \%$ weighted mean recall is obtained with $87.08 \%$ weighted mean precision and $96.84 \%$ accuracy, so that the proposed model is considered to have given good and accurate results. The classification results of the menu engineering implementation with the proposed model can be used to provide strategies to MSMEs in managing prices, product marketing, etc., to increase MSME business profits.

\section{REFERENCES}

[1] M. dan Lazuardi and M. S. Triady, Ekonomi Kreatif: Rencana Pengembangan Kuliner Nasional 2015-2019. 2015.

[2] Yuliawati, "Lima Sektor Harapan Ekonomi 2020 di Tengah Kegalauan Global," katadata.co.id, 2020

[3] B. P. S. Badan Ekonomi Kreatif, "Infografis Ringkasan Data Statistik Ekonomi Kreatif Indonesia," 2018.

[4] S. S. U. dan Pendapatan, Ed., Upah Tenaga Kerja Ekonomi Kreatif 2011-2016. Badan Pusat Statistik, 2017.

[5] H. G. Parsa, J. P. I. van der Rest, S. R. Smith, R. A. Parsa, and M. Bujisic, "Why Restaurants Fail? Part IV: The Relationship between Restaurant Failures and Demographic Factors," Cornell Hosp. Q., vol. 56, no. 1, pp. 80-90, 2015, doi: 10.1177/1938965514551959.

[6] H. G. Parsa, J. T. Self, D. Njite, and T. King, "Why restaurants fail," Cornell Hotel Restaur. Adm. Q., vol. 46, no. 3, pp. 304-322, 2005, doi: 10.1177/0010880405275598.

[7] H. Parga, A. Gregory, and M. D. Terry, "why do restaurants fail? part iii: an analysis of macro and micro factors," 2010.

[8] J. Trafialek, E. Czarniecka-Skubina, J. Kulaitiené, and N Vaitkevičiene, "Restaurant'smultidimensional evaluation concerning food quality, service, and sustainable practices: A cross-national case study of Poland and Lithuania," Sustain., vol. 12, no. 1, 2020, doi: $10.3390 /$ SU12010234

[9] N. M. Nassar and A. F. Al Zoubi, "The Impact of the Restaurants Services Quality on Customers Satisfaction in Aqaba Special Economic Zone Authority (ASEZA)," J. Soc. Sci., vol. 7, no. 2, pp. 157-171, 2018, doi: 10.25255/jss.2018.7.2.157.171.

[10] A. E. Baiomy, E. Jones, and M. M. H. Goode, "The influence of menu design, menu item descriptions and menu variety on customer satisfaction. A case study of Egypt," Tour. Hosp. Res., vol. 19, no. 2, pp. 213-224, 2019, doi: 10.1177/1467358417708228.

[11] Y. Zhong and H. C. Moon, "What Drives Customer Satisfaction, Loyalty, and Happiness in Fast-Food Restaurants in China? Perceived Price, Service Quality, Food Quality, Physical Environment Quality, and the Moderating Role of Gender," MDPI, vol. 9, pp. 1-19, 2020.

[12] I. G. N. D. P. Putra, I. A. Elistyawati, and I. M. D. Oka, "The Application of Menu Appetizer Based On Menu Engineering To Increase Selling Volume In El Patio Restaurant, Sol Beach House Benoa Bali," J. Appl. Sci. Travel Hosp., vol. 1, no. 2, pp. 178-187, 2018.

[13] O. Nebioğlu, "Review of Menu Management Process Model with a Case Study," Adv. Hosp. Tour. Res., vol. 9100, pp. 203-234, 2020, doi: 10.30519/ahtr.668220.

[14] I. Alva, J. Rojas, and C. Raymundo2, "Improving Processes Through the Use of the 5S Methodology and Menu Engineering to Reduce Production Costs of a MSE in the Hospitality Sector in the Department of Ancash," in International Conference on Human Interaction and Emerging Technologies, 2020, pp. 818-824.

[15] R. Linassi, A. Alberton, and S. V. Marinho, "Menu engineering an activity-based costing: An improved method of menu planning," Int. J Contemp. Hosp. Manag., vol. 28, no. 7, pp. 1417-1440, 2016, doi: 10.1108/JJCHM-09-2014-0438.

[16] M. Tom and K. Annaraud, "A fuzzy multi-criteria decision-making model for menu engineering," IEEE Int. Conf. Fuzzy Syst., 2017, doi 10.1109/FUZZ-IEEE.2017.8015612.

[17] Y. A. Gerhana, A. R. Atmadja, W. B. Zulfikar, and N. Ashanti, "The implementation of K-nearest neighbor algorithm in case-based reasoning model for forming automatic answer identity and searching answer similarity of algorithm case," 2017 th Int. Conf. Cyber IT Serv. Manag. CITSM 2017, pp. 3-7, 2017, doi 10.1109/CITSM.2017.8089233

[18] A. E. Mohamed, "Comparative Study of Four Supervised Machine Learning Techniques for Classification," Int. J. Appl. Sci. Technol., vol. 7, no. 2, pp. 5-18, 2017, doi: 10.15546/aeei-2014-0021.

[19] D. Bzdok, M. Krzywinski, and N. Altman, "Machine learning: supervised methods," Nat. Methods, vol. 15, no. 1, pp. 5-6, 2018, doi 10.1038/nmeth.4551.

[20] E. G. Nihad, E. N. El Mokhtar, Z. Abdelhamid, and A. A. Mohammed, "Hybrid approach of the fuzzy C-means and the K-nearest neighbors methods during the retrieve phase of dynamic case based reasoning for personalized follow-up of learners in real time," Int. J. Electr. Comput. Eng. vol. 9, no. 6, pp. 4939-4950, 2019, doi: 10.11591/ijece.v9i6.pp4939-4950.

[21] M. J. Alhasan, S. M. Abdulhussein, and A. H. K. Khwayyir, "Fingerprint positioning of users devices in long term evolution cellular network using K nearest neighbour algorithm," Int. J. Electr. Comput. Eng., vol. 11, no. 1, p. 528, 2021, doi 10.11591/ijece.v11i1.pp528-535

[22] A. A. N. Gunawan, I. Wayan Supardi, S. Poniman, and B. G. Dharmawan, "The utilization of physics parameter to classify histopathology types of invasive ductal carcinoma (IDC) and invasive lobular carcinoma (ILC) by using k-nearest neighbourhood (KNN) method," Int. J. Electr. Comput. Eng., vol. 8, no. 4, pp. 2442-2450, 2018, doi: 10.11591/ijece.v8i4.pp2442-2450.

[23] W. Lumchanow and S. Udomsiri, "Image classification of malaria using hybrid algorithms: convolutional neural network and method to find appropriate K for K-nearest neighbor," Indones. J. Electr. Eng. Comput. Sci., vol. 16, no. 1, p. 382, 2019, doi: 10.11591/ijeecs.v16.i1.pp382-388.

[24] I. D. M. Siñel1 and B. E. V. Comendador, "Rate movie app Implementation of k-nearest neighbors algorithm in the development of decision support system for Philippine movie rating and classification," Int. J. Adv. Sci. Eng. Inf. Technol., vol. 9, no. 1, pp. 9299, 2019, doi: 10.18517/ijaseit.9.1.7579.

[25] L. Le, Y. Xie, and V. V. Raghavan, "Deep Similarity-Enhanced K Nearest Neighbors," Proc. - 2018 IEEE Int. Conf. Big Data, Big Data 2018, pp. 2643-2650, 2019, doi: 10.1109/BigData.2018.8621894.

[26] D. Yan, Y. Wang, J. Wang, H. Wang, and Z. Li, "K-nearest Neighbor Search by Random Projection Forests," Proc. - 2018 IEEE Int. Conf. Big Data, Big Data 2018, pp. 4775-4781, 2019, doi: 10.1109/BigData.2018.8622307.

[27] G. Harsemadi, M. Sudarma, and N. Pramaita, "Implementasi Algoritma K-Nearest Neighbor pada Perangkat Lunak Pengelompokan Musik untuk Menentukan Suasana Hati," Maj. Ilm. Teknol. Elektro, vol. 16, no. 1, pp. 14-20, 2017, doi: 10.24843/mite.1601.03.

[28] W. Cherif, "Optimization of K-NN algorithm by clustering and reliability coefficients: Application to breast-cancer diagnosis," Procedia Comput. Sci., vol. 127, pp. 293-299, 2018, doi: 10.1016/j.procs.2018.01.125.

[29] M. L. Kasavana and D. Smith, Menu Engineering: A Practical Guide 
to Menu Analysis. Lansing, MI: Hospitality Publications, 1982.

[30] B. M. Noone and G. Cachia, "Menu engineering re-engineered: Accounting for menu item substitutes in pricing and menu placement decisions,” Int. J. Hosp. Manag., vol. 87, no. February, p. 102504, 2020, doi: 10.1016/j.ijhm.2020.102504

[31] N. Setiyawati et al., "Penerapan Metode Two-Step Cluster Dalam Analisis Menu the Implementation of Two-Step Clustering Method in Menu," vol. 7, no. 2, 2020, doi: 10.25126/jtiik.202072012.

[32] S. Xia, G. Wang, Y. Liu, Q. Liu, and H. Yu, "Noise self-filtering Knearest neighbors algorithms," Proc. - 2017 IEEE Int. Conf. Big Data, Big Data 2017, vol. 2018-Janua, pp. 1860-1865, 2017, doi: 10.1109/BigData.2017.8258130.

[33] G. Rigas, "Menu Profitability Analysis Models: Linking Theory and Practice in the Greek Hospitality Context," no. December 2019, [Online]. https://repository.ihu.edu.gr/xmlui/handle/11544/29230.

[34] S. Arsic, D. Pamucar, and M. Suknovic, "Determining The Weights of Criteria in Menu Evaluation Using Best-Worst Method," in XVI International symposium Symorg 2018: Doing Business in The Digital Age: Challenges, Approaches and Solutions, 2018, pp. 292-297.

[35] D. V. Pavesic, "Cost/margin analysis: a third approach to menu pricing and design," Int. J. Hosp. Manag., vol. 2, no. 3, pp. 127-134, 1983, doi: 10.1016/0278-4319(83)90033-6.

[36] M. Sandeep, "Menu Engineering Model To Menu of a Resort Restaurant- a Case Study Approach," 1997.

[37] R. Adeng and A. Firman, "Improvement of The Operation for KOPIBIKE Restaurant Using Menu Engineering Approach," Indones. J. Bus. Adm., vol. 2, no. 6, pp. 672-680, 2013.

[38] S. M. LeBruto, W. J. Quain, and R. A. Ashley, "Menu engineering: a model including labor," Hosp. Rev., vol. 13, no. 1, pp. 41-49, 1995.

[39] B. W. Horton, "Labor and menu category: effects on analysis," Hosp. Rev., vol. 19 , no. 2 , pp. $35-46,2001$

[40] K. Huang, Y.-W. Wen, and C.-K. Ting, "Enhancing k -Nearest
Neighbors through Learning Transformation Functions by Genetic Programming," in 2019 IEEE Congress on Evolutionary Computation, CEC 2019 - Proceedings, 2019, no. 1, pp. 1891-1897.

[41] A. Millana et al., "Optimisation of children z-score calculation based on new statistical techniques," PLoS ONE 13, pp. 1-14, 2018, doi: https://doi.org/10.1371/journal.pone.0208362 December.

[42] S. Raschka, "Model Evaluation, Model Selection, and Algorithm Selection in Machine Learning," 2018.

[43] H. B. Moss, D. S. Leslie, and P. Rayson, "Using J-K-fold cross validation to reduce variance when tuning NLP models," arXiv, pp. 2978-2989, 2018

[44] C. A. Ramezan, T. A. Warner, and A. E. Maxwell, "Evaluation of Sampling and Cross-Validation Tuning Strategies for Regional-Scale Machine Learning Classification," Remote Sens., 2019, doi: $10.3390 /$ rs 11020185 .

[45] H. Sujaini, "Image Classification of Tourist Attractions with KNearest Neighbor, Logistic Regression, Random Forest, and Support Vector Machine," Int. J. Adv. Sci. Eng. Inf. Technol., vol. 10, no. 6, pp. 2207-2212, 2020, doi: 10.18517/ijaseit.10.6.9098.

[46] Y. Zhongguo, L. Hongqi, Z. Liping, L. Qiang, and S. Ali, "A case based method to predict optimal k value for k-NN algorithm," J. Intell. Fuzzy Syst., vol. 33, pp. 55-65, 2017, doi: 10.3233/JIFS-161062.

[47] R. Rizaldi, A. Kurniawati, and C. V. Angkoso, "Implementasi Metode Euclidean Distance untuk Rekomendasi Ukuran Pakaian pada Aplikasi Ruang Ganti Virtual," J. Teknol. Inf. dan Ilmu Komput., vol. 5, no. 2, p. 129, 2018, doi: 10.25126/jtiik.201852592.

[48] X. Wang, Y., Li, J., Li, Y., Wang, R., \& Yang, "Confidence interval for F1 mea- sure of algorithm performance based on blocked $3 \times 2$ cross-validation," IEEE Trans. Knowl. Data Eng., vol. 27, pp. 651659, 2015.

[49] P. Galdi and R. Tagliaferri, "Data Mining: Accuracy and Error Measures for Classification and Prediction," Elsevier, no. January, pp. 1-15, 2017, doi: 10.1016/B978-0-12-809633-8.20474-3. 